\title{
Multivariate Study and Analysis of the Production of Citric Acid from Dates by Surface Method
}

\author{
Khalid Al-Shoaily*, Mansoura Al-Amri, Fouzia Al-Rawahi, Muhammad Al-Sidrani, \\ Amal Al-Ghafri \\ Food Processing Research Laboratory, Ministry of Agriculture \& Fisheries, Muscat, Oman \\ Email: ${ }^{*}$ kalshoaily@yahoo.com
}

Received January 2014

\begin{abstract}
The production of citric acid from dates of the date palm Phoenix dactilifera was studied using a full factorial design with two design variables; Aspergillus niger strain, and starter juice treatment. Analyses of data have shown that mould type and the interaction between Aspergillus niger strain + juice treatment had significant effect $(P \geq 0.05)$ on the final total acidity. It was also found that all design variables and the interaction between them had significant effect $(P \geq 0.05)$ on the final $\mathrm{pH}$ and Total Soluble Solids. The highest total acidity expressed as citric acid was achieved with a commercial strain of Aspergillus niger, and filtered and centrifuged date juice.
\end{abstract}

Keywords

Dates; Citric; Aspergillus niger

\section{Introduction}

Dates continue to be the most abundantly produced fruit in Oman; the annual total yield according to ministry of agriculture and fisheries (MAF) Oman 2010 estimation was 276,405 tons. Although potentially there is very valuable raw material for many industries, the almost exclusive use of dates is still direct consumption. The high content of monosaccharides (glucose, and fructose) (Al-Farsi, Alasalvar et al. 2007) [1] makes the dates suitable for fermentation to produce various organic acids such as acetic acid and citric acid.

Citric acid is an organic acid that naturally occurs in fruits such as lemons oranges, and may be synthesised from glycerol (Kristiansen Bjorn, Mattey et al. 1999) [2]. It is also produced via fermentation by microorganisms action, many microorganisms accumulate citric acid, among them is Aspergillus niger, A. awamori, Absidia sp, Acremonium sp. ...etc. Nowadays Aspergillus niger is almost exclusively used to produce citric acid at industrial scale (Kristiansen Bjorn, Mattey et al. 1999) [2]. Citric acid has a wide range of use in food and beverage, in preparation of numerous industrial products, pharmaceuticals, and as a cleaning agent (Lotfy Walid A, Ghanem Khaled M. et al. 2007) [3]. Factorial experimental design and multivariate analysis is a useful tool used

\footnotetext{
${ }^{*}$ Corresponding author.
}

How to cite this paper: Al-Shoaily, K., et al. (2014) Multivariate Study and Analysis of the Production of Citric Acid from Dates by Surface Method. Journal of Agricultural Chemistry and Environment, 3, 20-25. 
to estimate the impact a parameter (a design variable) has on a response ( non design variable ), this design is used for screening purpose to study main effects and interactions between combinations between design variables (Esbensen, Guyot et al. 2004) [4].

In the work reported here, we attempt to study the effects of two design variables (juice treatment, and mould type) on three non design variables (pH, total acidity, and total soluble solids TSS) in an experiment to produce citric acid by surface method from date juice.

\section{Materials and Method}

\subsection{Microorganism}

Two mould types were used in this study: a commercial strain of Aspergillus niger supplied by Culti-loops (the code is kept), and the other is a local strain of Aspergillus niger isolated from local dates surface.

\subsection{Inoculum}

Loops from pre prepared pure slants of Aspergillus niger (local or commercial) were streaked (Figure 1) on potato dextrose agar (Supplied by Himedia-India), and used to inoculate $18^{\circ}$ brix date juice, then placed in a shaker incubator at $30^{\circ} \mathrm{C}$ for 48 hours to produce pellets (Abid M. Al-, Al-Amri M. et al. 2010) [5].

\subsection{Preparation of Date Juice}

Dates sugars were extracted with water as explained in (Abid M. Al-, Al-Amri M. et al. 2010) [5], the final TSS was adjusted at $18^{\circ}$ brix. The juice was subsequently treated in one of two filtration ways:

1) Filtration with whatman No.1 filter paper or

2) Filtration with whatman No.1 filter paper followed by centrifugation at 4000 RPM.

\subsection{Inoculation with Aspergillus niger}

Two types of Aspergillus niger, a commercial strain, and a local strain isolated from the surface of dates were used to inoculate the date juice.

\subsection{Treatment with Tricalcium Phosphate (TP)}

To eliminate inhibition caused by metals the date juice was treated with Tricalcium Phosphate Treatment to chelate minerals as explained in (Roukas T. and P.) [6] and (Abid M. Al-, Al-Amri M. et al. 2010) [5].

\subsection{Analytical Methods}

Total acidity was by titration with $\mathrm{NaOH}, \mathrm{pH}$ was measured with $\mathrm{pH}$ meter (WTW, supplied by, Germany), TSS by bench top refractometer BS supplied by Stanley \& Bellingham, UK

\subsection{Experimental Design}

A full factorial design was implemented with 2 design variables and 3 non design variables as shown in Figure 2 \& Table 1, the treatments were performed in triplicates:

\subsection{Data analysis}

All analysis of data were performed with MINITAB14.

\section{Results and Discussions}

Total acidity, $\mathrm{pH}$, and total soluble solids were monitored daily in order to determine the pattern at which the changes occur.

Acidity of fermenting medium was used as an indication of acid production. The total acidity increased slowly up to day eight then exponentially up to day 14 and leveled (Figure 3). 


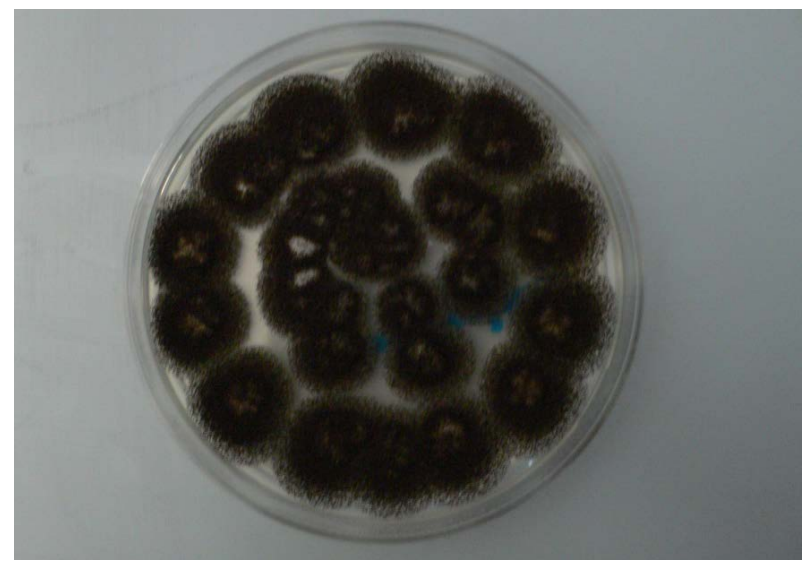

Figure 1. Aspergillus niger growth on PDA.

Table 1. Design variables (factors) and non design variables used.

\begin{tabular}{|c|c|}
\hline Design variables & Non design variables \\
\hline $\begin{array}{l}\text { 1) Filtration treatment: } \\
\text { a) Filtration through whatman filter( }\left(\mathrm{T}_{1}\right) \text {. } \\
\text { b) Centrifugation at } 4000 \mathrm{RPM}\left(\mathrm{T}_{2}\right) \text {. } \\
\text { 2) Inoculum type: } \\
\text { a) Local strain Aspergillus niger }\left(\mathrm{S}_{1}\right) \text {. } \\
\text { b) Commercial strain Aspergillus niger }\left(\mathrm{S}_{2}\right) \text {. }\end{array}$ & $\begin{array}{l}\text { 1) } \mathrm{pH} \\
\text { 2) Total soluble solids TSS } \\
\text { 3) Total acidity. }\end{array}$ \\
\hline
\end{tabular}

\subsection{Optimization of Fermentation Conditions}

A full factorial design was implemented as shown in Figure 2 \& Table 1, this design is used for screening design variables (juice treatment and Aspergillus niger strain) in order to find out about main effects they have on non design variables or responses ( $\mathrm{pH}$, total acidity, and total soluble solids TSS) of the final product, in addition to interaction effects of the design variables (Esbensen, Guyot et al. 2004) [4].

\subsection{Effect of Mould Type on Final Total Acidity}

The final analysis results are shown in Table 2 . The mould type significantly affected the total acidity $(P \geq 0.05)$, total acidity increased from 0.37 , to 3.75 , and from 1.18 to $3.58 \%$ by changing the mould type from local $\left(\mathrm{S}_{1}\right)$, to commercial $\left(\mathrm{S}_{2}\right)$ strains respectively.

\subsection{Effect of Mould Type on Final pH}

The final $\mathrm{pH}$ was significantly affected by mould type $(P \geq 0.005)$, the final $\mathrm{pH}$ (Figure 4 ) was reduced from 3.74 , to 2.57 , and from 2.9 to 2.58 by changing the mould type from local $\left(\mathrm{S}_{1}\right)$, to commercial $\left(\mathrm{S}_{2}\right)$ strains respectively.

\subsection{Effect of Mould Type on Final TSS}

The final total soluble solids TSS of the final product was used as an indication of sugar assimilation by Aspergillus niger (Figure 5). The mould type significantly ( $P \geq 0.005)$, affected the TSS. The readings of TSS of the final product Table 2 show decrease in TSS values from 14 to 13.8, and from 15.5 to 13.03 with change of mould type from local $\left(\mathrm{S}_{1}\right)$, to commercial $\left(\mathrm{S}_{2}\right)$ strains respectively.

\subsection{Effect of Juice Treatment on Final Total Acidity}

As can be seen in Table3 the juice treatment had insignificant effect alone on total acidity $(P \geq 0.05)$, but the interaction with the mould type was significant $(P \geq 0.05)$ (see Table 3). 


\section{Full factorial design to study the Production of citric acid from dates} by surface method

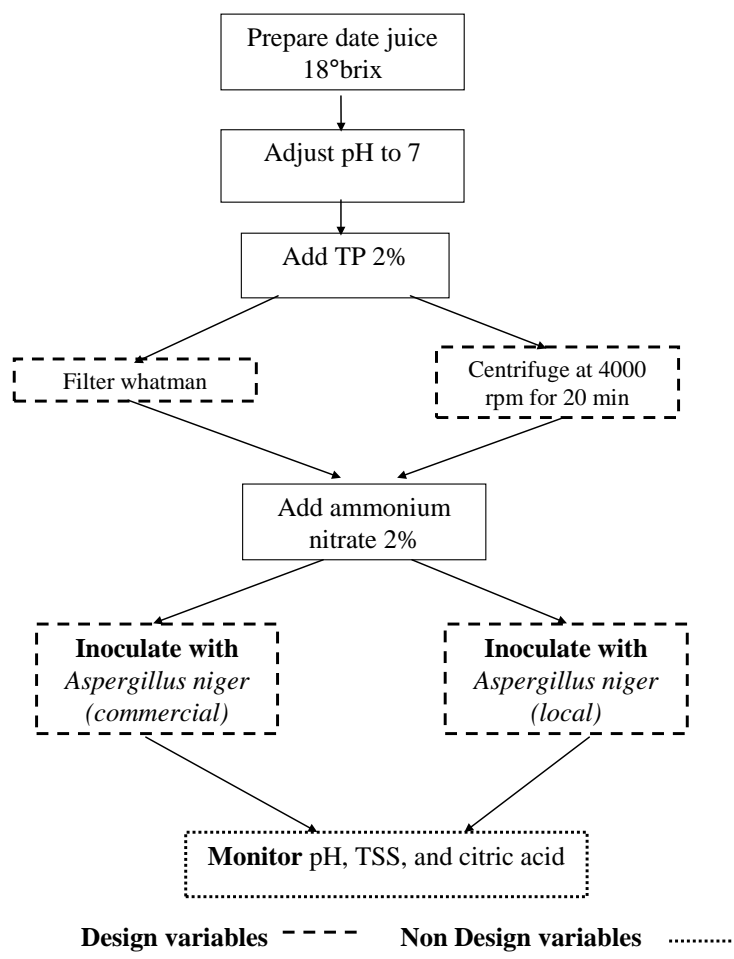

Figure 2. A process flow diagram showing design variables and non design variables.

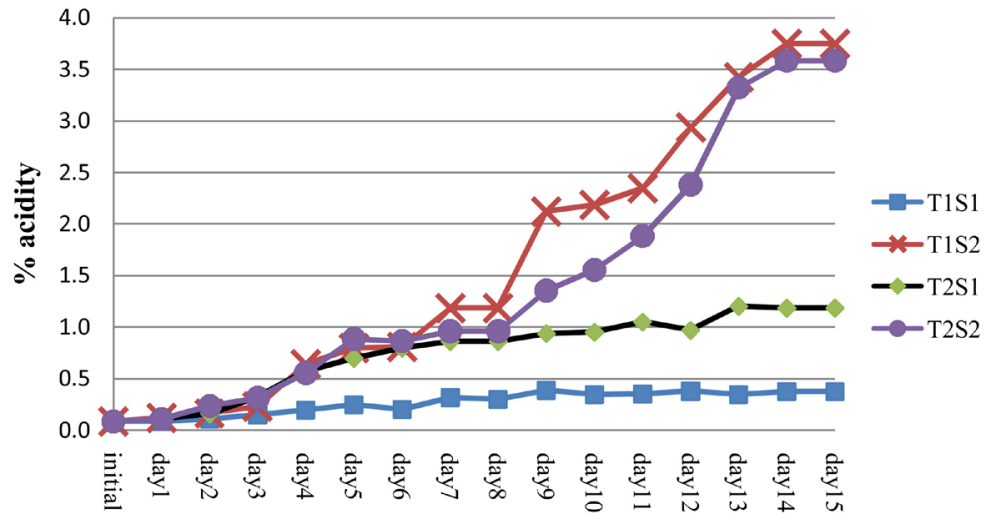

Figure 3. Changes in acidity of fermented medium. $\mathrm{T}_{1} \mathrm{~S}_{1}$ juice treatment 1 and mould type $1 ; T_{1} S_{2}$ juice treatment 1 and mould type 2; $T_{2} S_{1}$ juice treatment 2and mould type $1 ; \mathrm{T}_{2} \mathrm{~S}_{2}$ juice treatment 2 and mould type 2 .

Table 2. Final results of acidity, pH, and TSS.

\begin{tabular}{cccc}
\hline & \% Acidity & pH & TSS ${ }^{\text {brix }}$ \\
\hline $\mathrm{T}_{1} \mathrm{~S}_{1}$ & 0.37 & 3.74 & 14.00 \\
$\mathrm{~T}_{1} \mathrm{~S}_{2}$ & 3.75 & 2.57 & 13.80 \\
$\mathrm{~T}_{2} \mathrm{~S}_{1}$ & 1.18 & 2.90 & 15.50 \\
$\mathrm{~T}_{2} \mathrm{~S}_{2}$ & 3.58 & 2.58 & 13.03 \\
\hline
\end{tabular}




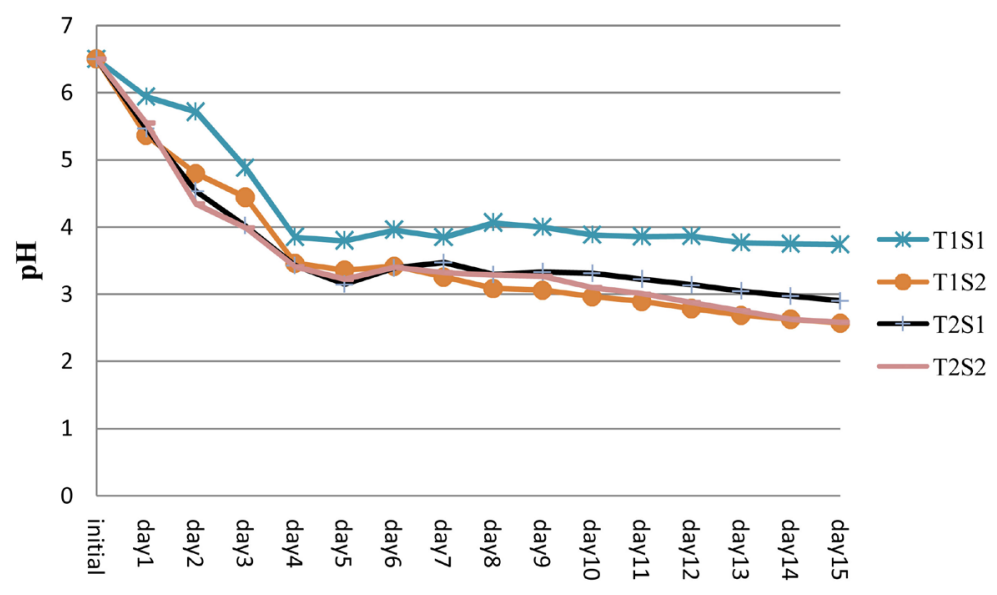

Figure 4. Changes in $\mathrm{pH}$ of fermented medium.

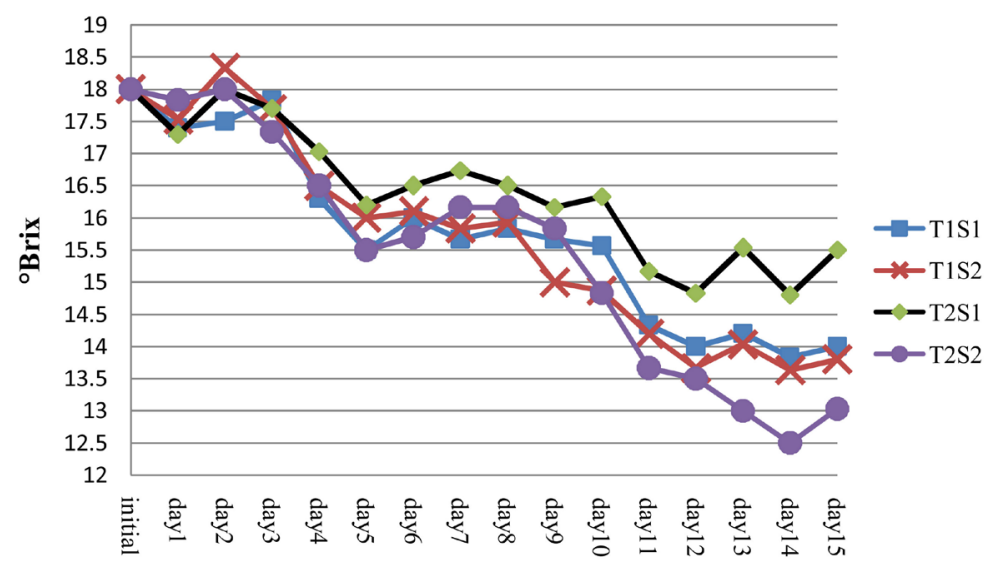

Figure 5. Changes in TSS of fermented medium.

\subsection{Effect of Juice Treatment on Final pH}

The final $\mathrm{pH}$ was significantly affected by juice treatment $(P \geq 0.005)$ (see Table 3 ), the final $\mathrm{pH}$ was reduced from 3.74, to 2.57 , and from 2.9 to 2.58 Table 2 by changing the juice treatment from local $\left(\mathrm{T}_{1}\right)$, to centrifugation $\left(\mathrm{T}_{2}\right)$ respectively.

\subsection{Effect of Juice Treatment on Final TSS}

The readings of TSS of the final product (Table 2) show decrease in TSS values from 14 to 13.8, and from 15.5 to 13.03 with change of juice filtration treatment from $\left(\mathrm{T}_{1}\right)$, to $\left(\mathrm{T}_{2}\right)$ respectively. The decrease was significant $(P$ $\geq 0.005$ ), which shows the need for thorough filtration technique.

\subsection{Analysis of Variance (One Way ANOVA)}

Analysis of variance (one way ANOVA) Table 4 shows that both parameters (main effects) used were significant, further more the interaction between mould type and juice treatment was significant as well.

\section{Conclusion}

The results revealed the significance of mould type and filtration technique in the production of citric acid from date juice. Despite the result the mould was more significant $(P \leq 0.005)$ than juice treatment $(P \geq 0.05)$; the combined effect of interaction between the two was significant $(P \leq 0.05)$. The maximum total acidity achieved 
Table 3. $\mathrm{P}$ values for non design variables versus design variables.

\begin{tabular}{cccc}
\hline Non design variables (responses) Design variable (factors) & Total acidity & pH & TSS \\
\hline Aspergillus niger strain & $0.000(* *)$ & $0.000(* *)$ & $0.020(*)$ \\
Juice treatment & $0.810(\mathrm{NS})$ & $0.000(* *)$ & $0.005\left({ }^{*}\right)$ \\
2 way interaction: Aspergillus niger strain + Juice treatment & $0.041(*)$ & $0.000(* *)$ & $0.020\left({ }^{*}\right)$ \\
\hline
\end{tabular}

$\left({ }^{* *}\right) P \leq 0.001,\left({ }^{*}\right) P \leq 0.05$, (NS) not significant.

Table 4. Analysis of variance (one way ANOVA).

\begin{tabular}{|c|c|c|c|}
\hline Non design variables (responses) Design variable (factors) & Total acidity & $\mathbf{p H}$ & TSS \\
\hline Main effects & $0.000(* *)$ & $0.000(* *)$ & $0.004(*)$ \\
\hline 2 way interaction & $0.041(* *)$ & $0.000(* *)$ & $0.020\left(^{*}\right)$ \\
\hline
\end{tabular}

(**) $P \leq 0.001,(*) P \leq 0.05$, (NS) not significant.

was 3.75\% by using the commercial strain of Aspergillus niger and centrifugation of the juice prior to fermentation. Using of factorial design showed the importance of interaction effect that the parameters had on the responses. Dates can be a promising material for production of citric acid.

\section{References}

[1] Al-Farsi, M., Alasalvar, C., et al. (2007) Compositional and Functional Characteristics of Dates, Syrups, and Their ByProducts. Food Chemistry, 104, 943-947. http://dx.doi.org/10.1016/j.foodchem.2006.12.051

[2] Kristiansen, B., et al. (1999) Citric Acid Biotechnology. Taylor \& Frances, London.

[3] Lotfy, W.A., Ghanem, K.M., et al. (2007) Citric Acid Production by a Novel Aspergillus niger Isolate: II. Optimization of Process Parameters through Statistical Experimental Designs. Bioresource Technology, 98, 3470-3477.

[4] Esbensen, K.H., Guyot, D., et al. (2004) Multivarialte Data Analysis in Practice. Camo Process AS, Oslo.

[5] Al-Abid, M., Al-Amri, M., et al. (2010) Applying Submerged Technique to Produce Citric Acid from Dates. ISHS Acta Horticulture, $\mathbf{8 8 2}$.

[6] Roukas, T. and Kotzekidou, P. (1997) Pretreatment of Date Syrup to Increase Citric Acid Production. Enzyme and Microbial Technology, 21, 273-276. 